\title{
Double C1 Posterior Arches
}

Sir,

Congenital anomalies of the posterior arch of the atlas (C1) are relatively common anomalies. They may range from partial defects presenting as clefts to complete absence of the posterior arch. However, presenting as double posterior $\mathrm{C} 1$ arch is extremely rare.

A 22-year-old male presented to us with head injury. Routine X-ray screening of the cervical spine revealed two posterior arches of the atlas [Figure 1]. However, the patient was asymptomatic apart from mild neck pain. Computed tomography (CT) scan of the cervical spine showed, both anterior and posterior splitting of the arch of atlas along with fusion of the dens to right side of the anterior arch [Figure 2]. Then with three-dimensional reconstruction in the CT scan, the posterior splitting of arches was at different level in the axial plane, which was seen as a double posterior component in lateral X-ray film. Furthermore, it was noted that the bodies of $\mathrm{C} 1$ and $\mathrm{C} 2$ were fused on the right side [Figures 3 and 4]. No further investigation like magnetic resonance imaging of cervical spine was ordered, as there was no neurological deficit. He was advised to wear a cervical collar and to have regular follow-up.

The reported incidence in a large study of 1613 autopsies with regard to the presence of congenital aplasia in the C1 vertebra is approximately $4 \%$ for the posterior arch and $0.1 \%$ for the anterior arch. ${ }^{[1]}$ However, the incidence would be higher as many cases do not go routine screening. The congenital defects of the posterior arch of the atlas may be discovered as incidental asymptomatic findings, but symptoms occurring after trauma to the head and neck or spontaneously also may be encountered. ${ }^{[2]}$

Three primary ossification centers have been described in the $\mathrm{C} 1$ vertebra: Anterior center, which forms the anterior tubercle; and two lateral centers, which form the lateral masses and the posterior arch. Defects of the posterior arch are thought to develop because of a failure of local chondrogenesis rather than subsequent ossification. ${ }^{[3]}$ The possibility of wide splitting of posterior arch and level of difference in axial plane in our case may be due to defective chondrogenesis.

In case of trivial neck trauma, one should investigate further to look for any fracture or and associated other congenital anomalies. It is important to be familiar with the differences between a congenital anomaly of the atlas and a Jefferson fracture and to exclude instability of the upper cervical spine before treatment is started. ${ }^{[4]}$ The developmental cleft margins are smooth with an intact cortical edge and no soft-tissue swelling. Conversely, fractures have jagged edges or are comminuted and generally are associated with soft-tissue swelling. ${ }^{[5]}$ No definitive guidelines exist for the management of this type of congenital anomaly. This is purely an incidental finding in an asymptomatic patient, and he only needs regular follow-up. In conclusion, $\mathrm{C} 1$ anomalies can present in various ways, and their management differs accordingly depending on the instability they produce. High degree of suspicion is required to diagnose such anomalies and appropriate treatment can be instituted whenever required. 


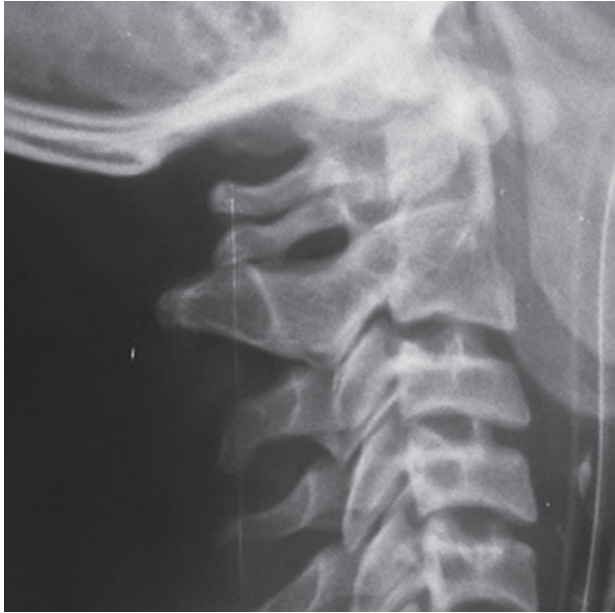

Figure 1: $\mathrm{X}$-ray cervical spine showing two $\mathrm{C} 1$ posterior arches

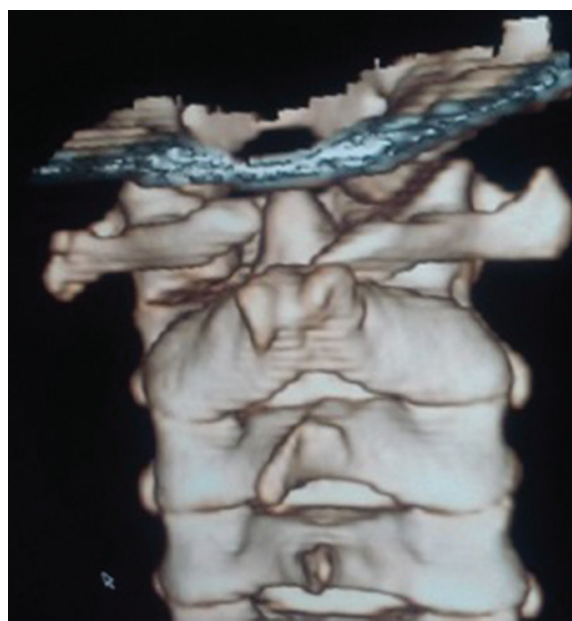

Figure 3: Three-dimensional computed tomography reconstruction of C1/C2 complex

\section{Financial support and sponsorship}

Nil.

\section{Conflicts of interest}

There are no conflicts of interest.

Pralaya Kishore Nayak

Department of Neurosurgery, Sparsh Hospital, Bhubaneswar, Odisha, India

Address for correspondence: Dr. Pralaya Kishore Nayak, Department of Neurosurgery, Sparsh Hospital, Saheed Nagar, Bhubaneswar - 751 007, Odisha, India. E-mail: drmichaelpn@gmail.com

\section{REFERENCES}

1. Pasku D, Katonis P, Karantanas A, Hadjipavlou A. Congenital posterior atlas defect associated with anterior rachischisis and early cervical degenerative disc disease: A case study and review of the literature. Acta Orthop Belg 2007;73:282-5.

2. Currarino G, Rollins N, Diehl JT. Congenital defects of the posterior arch of the atlas: A report of seven cases including an affected mother and son. AJNR Am J Neuroradiol $1994 ; 15: 249-54$.

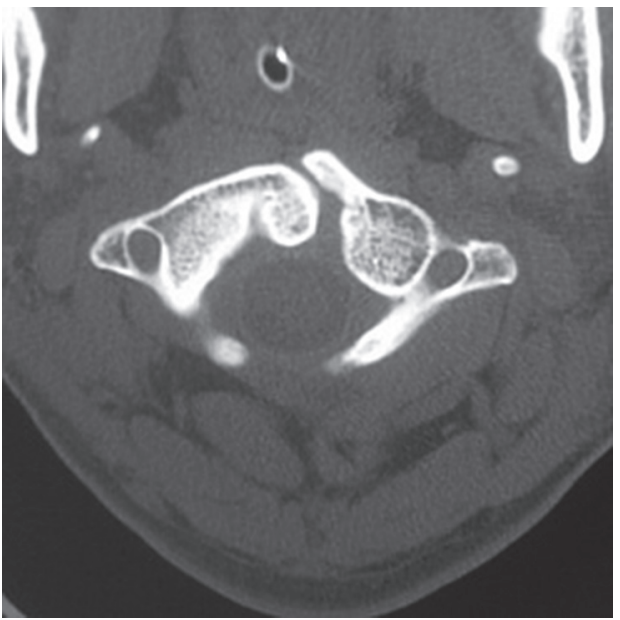

Figure 2: Spinal computed tomography showing congenital anomaly of $\mathrm{C} 1$

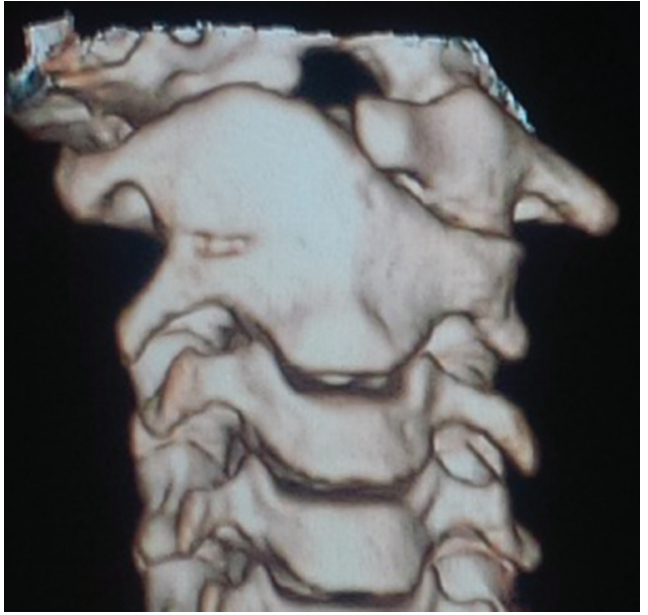

Figure 4: Dens fused to right half of $\mathrm{C} 1 \mathrm{arch}$

3. Elmalky MM, Elsayed S, Arealis G, Mehdian H. Congenital C1 arch deficiency: Grand Round presentation. Eur Spine J 2013;22:1223-6.

4. de Zoete A, Langeveld UA. A congenital anomaly of the atlas as a diagnostic dilemma: A case report. J Manipulative Physiol Ther 2007;30:62-4.

5. Dorne HL, Lander PH. CT recognition of anomalies of the posterior arch of the atlas vertebra: Differentiation from fracture. AJNR Am J Neuroradiol 1986;7:176-7.

This is an open access article distributed under the terms of the Creative Commons Attribution-NonCommercial-ShareAlike 3.0 License, which allows others to remix, tweak, and build upon the work non-commercially, as long as the author is credited and the new creations are licensed under the identical terms.

\begin{tabular}{|l|l}
\hline \multicolumn{2}{|c}{ Access this article online } \\
\hline Quick Response Code: & Website: \\
\hline & www.ruralneuropractice.com \\
& \\
&
\end{tabular}

How to cite this article: Nayak PK. Double C1 posterior arches. J Neurosci Rural Pract 2017;8:S161-2.

(c) 2017 Journal of Neurosciences in Rural Practice | Published by Wolters Kluwer - Medknow 